\begin{abstract}
The aim of our study has been to assess the comparative use of the two NSAIDs, dexketoprofen and ketoprofen, for postoperative analgesia after laparoscopic cholecystectomy mainly following: the quality of the analgesia, the incidence of potential adverse effects (for example, postoperative nausea and vomiting) and the rescue analgesics consumption (tramadol). This prospective, randomized, double-blind study included 90 patients undergoing laparoscopic cholecystectomy under general anaesthesia. Patients were randomly assigned into 2 groups: group $\mathrm{D}(\mathrm{n}=45)$ - patients that have received dexketoprofen $50 \mathrm{mg}$ in dilution with $10 \mathrm{ml}$ saline solution iv., 30 minutes before the induction and group $\mathrm{K}(\mathrm{n}=45)$ - patients that have received ketoprofen $100 \mathrm{mg}$ in dilution with $10 \mathrm{ml}$ saline solution iv., 30 minutes before the induction (preemptive analgesia). Surgical interventions were conducted under general anaesthesia, with identical protocol for the two groups of study. Post-surgery analgesic regime consisting in $4 \mathrm{~g}$ of paracetamol administered for example in the first 24 hours, was started immediately after surgery. Boluses of tramadol of $100 \mathrm{mg}$ (until $400 \mathrm{mg} /$ daily) have been used as rescue analgesia. The main objectives of our study have been: post-surgery analgesia (VAS at mobilization, 0-100 $\mathrm{mm}$ ) at $0,2,6,12$ and 24 hours after the surgery,
\end{abstract}

\section{Viorel Gherghina}

Faculty of Medicine, Ovidius University, Constanta

E-mail : gherghina_v@yahoo.co.uk the consumption of tramadol, incidence of PONV and the length of hospitalization period (LOS). Secondary objectives of the study have been: the incidence of gastrointestinal symptoms and the incidence of postsurgery blood losses. In the two study groups there have not been any differences concerning demographic data, post-surgery gastro-intestinal symptoms, postsurgery loss of blood and the hospitalization period. VAS was significantly lower in group $\mathrm{D}$ vs. $\mathrm{K}$, at 0 and 6 hours after the surgery $(p<0,05)$. The incidence of PONV was lower in the group of patients who received preemptive analgesia with dexketoprofen $(p<0,05)$. The number of tramadol boluses administered and the number of patients requiring backup analgesia was lower in group D comparatively to group K. Preemptive administration of dexketoprofen seems to be more effective than the administration of ketoprofen for post-surgery multimodal analgesia after laparoscopic cholecystectomy. The preemptive administration of dexketoprofen also deereases tramadol consumption and the incidence of postoperative nausea and vomiting.

Keywords: dexketoprofen, ketoprofen, multimodal analgesia, nausea, vomiting

\section{Introduction}

Postoperative pain is a particular form of acute pain that occurs in response to damaged tissue caused by surgical act, being the expression of autonomic responses, psychological and behavioural causes, an 
unpleasant and undesirable sensory and emotional experience $[1,2,3]$.

Efficient management of acute postoperative pain is a humanitarian act which directly influences the recovery and hospitalization period of the patient, with considerable medical, economic and social implications [4].

Anti-inflammatory drugs (NSAIDs) are the basic components of multimodal post-surgery analgesia in laparoscopic surgery. However, a substantial number of patients require back-up analgesics, such as opioids, at least the first 24 hours after surgery. These analgesics have adverse effects which can delay early mobilization and rapid postsurgery discharge $[5,6]$.

The aim of our study has been to comparatively assess the usage of the two NSAIDs, dexketoprofen (Tador ${ }^{\circledR}$ - ampoules of $50 \mathrm{mg} / 2 \mathrm{ml}$ ) and ketoprofen (Ketonal ${ }^{\circledR}$ - ampoules of $100 \mathrm{mg} / 2 \mathrm{ml}$ ), for postsurgery analgesia after laparoscopic cholecystectomy, mainly following: the quality of analgesia, the incidence of potential adverse effects (for example postoperative nausea and vomiting increased by the use of opioid analgesics) and analgesic back-up administered doses (tramadol).

\section{Material and method}

This perspective, randomized, double-blind study was approved by the Ethics Committee of Constanta County Emergency Hospital, and was held between March 1st, 2012 - September 1st, 2012 and it included 90 patients proposed for laparoscopic cholecystectomy.

Criteria for inclusion of patients in the study were: elective surgery (diagnosed with chronic cholecystitis), aged 18- 80 years old, ASA I - III class, absence of classical surgeries in the upper abdomen.

Exclusion criteria from the study of patients have been: acute cholecystitis, a history of hypersensitivity and intolerance to NSAIDs, history of upper gastrointestinal bleeding or ulcer pathology, heart failure, moderate or severe renal or hepatic impairment.

The day before the surgery, during the preanesthetic consultations, patients signed the informed consent and received written and verbal instructions on the study protocol.

Patients were randomly assigned by the random number list method into two groups as follows: group $\mathrm{D}$ (Dexketoprofen) -45 patients who have received 30 minutes before the induction an intravenous injection of $50 \mathrm{mg}$ dexketoprofen diluted with physiological saline up to $10 \mathrm{ml}$, and the $\mathrm{K}$ group (ketoprofen) 45 patients who have received 30 minute before the induction an intravenous injection of $100 \mathrm{mg}$ of ketoprofen diluted with physiological saline up to 10 $\mathrm{ml}$. The content of the two syringes (dexketoprofen dilution, respectively, ketoprofen) was prepared by a member of the study team, not involved in the conduct of surgery or in the immediate post-surgery monitoring (first 24 hours).

All the patients have received the same anaesthesia scheme: premedication with midazolam $2.5 \mathrm{mg}$ iv., fentanyl induction $0.02 \mu \mathrm{g} / \mathrm{kg}$, propofol $1.5 \mathrm{mg} / \mathrm{kg}$ and rocuronium $0.6 \mathrm{mg} / \mathrm{kg}$; maintenance has been done with sevoflurane $4 \%$ in oxygen $100 \%$ $0.51 / \mathrm{min}$ (minimum flux). Awakening was facilitated with nalorphine boluses $0.1 \mathrm{mg}$ and combination of atropine $0.5 \mathrm{mg}$ and neostigmine $0.025 \mathrm{mg} / \mathrm{kg}$, according to need. The fluid regime used intrasurgically was of liberal type. In all cases, $4 \mathrm{mg}$ of dexamethasone and $50 \mathrm{mg}$ of ranitidine (gastric protection) have been intravenously administered immediately after the induction.

If during the surgery a conversion to conventional cholecystectomy was required, that patient was withdrawn from the final evaluation. Moreover, acute pus cholecystitis intra-surgically discovered, regardless of the way the surgery was continued, it led to the elimination of the patient from the study.

At the end of the surgery, all patients received $1 \mathrm{~g}$ paracetamol (Perfalgan $\AA-10 \mathrm{mg} / \mathrm{ml}$, vials of $100 \mathrm{ml}$ ) by infusion, being later repeated from 6 to 6 hours, until reaching $4 \mathrm{~g}$ in the first 24 hours after the surgery. As backup analgesic (at VAS $>4 \mathrm{~cm}$ ) tramadol was used (Tramadol ${ }^{\circledR}$ - ampoules 100 $\mathrm{mg} / 2 \mathrm{ml}$ ), in boluses of $100 \mathrm{mg}$ iv, repeated until a 
maximum of $400 \mathrm{mg}$ in 24 hours.

In this study, we have aimed at:

- post-surgery analgesia quality of awakening from anaesthesia and at 2, 6, 12, 24 hours after the surgery, appreciated on the VAS scale, from 0 to $100 \mathrm{~mm}$;

- incidence of post-surgery nausea and vomiting (PONV); patients have been divided, according to severity, into three categories: only nausea, a vomiting episode, several episodes of vomiting;

- consumption of tramadol;

- hospitalization period (days);

- incidence of adverse effects associated with NSAIDs (intra and post- surgery bleeding).

- Monitoring was performed by a „blind” observer of randomized patients.

Statistical analysis was performed using SPSS program for Windows, variant 16.0, using Student $t$ tests and ANOVA univariate for quantitative variables (demographic parameters, VAS, backup analgesic consumption, hospitalization period) and the U MannWhitney test for qualitative variables (nausea and vomiting, gastrointestinal symptoms, perioperative bleeding etc.). Results are expressed as average values \pm standard deviation. A confidence interval of $>95 \%$ was considered statistically significant $(p<0,05)$.

\section{Results}

A total number of 118 patients have been scheduled for laparoscopic cholecystectomy over the course of our study. Among these, 28 (23.72\%) have not been included into the study since they have not met the selection criteria. The rest of 90 patients have been randomly divided into two groups: group D (Dexketoprofen) and group K (Ketoprofen).

6 patients have not completed the post-surgery study and have been excluded from the analysis of post-surgery data due to a conversion in classical cholecystectomy ( 2 patients from each group) and due to the intra-surgery diagnosis of acute puscholecystitis ( 2 patients from group D). No significant intra-surgery bleedings have been reported.

Demographic data of the two groups are presented in Table I.

Table I - Patient demographic data and clinical characteristics

\begin{tabular}{|l|c|c|c|}
\hline & $\begin{array}{c}\text { Grup D } \\
(\text { Dexketoprofen }) \\
(\mathrm{n}=41)\end{array}$ & $\begin{array}{c}\text { Grup K } \\
(\text { Ketoprofen }) \\
(\mathrm{n}=43)\end{array}$ & $\mathrm{p}$ \\
\hline Age $(\mathrm{yrs})$ & $52.9 \pm 6,1$ & $54.55 \pm 9.7$ & 0.48 \\
\hline Weight $(\mathrm{kg})$ & $61.8 \pm 10.6$ & $66.5 \pm 5.2$ & 0.71 \\
\hline Height $(\mathrm{cm})$ & $160.4 \pm 11.1$ & $167.4 \pm 10.8$ & 0.18 \\
\hline Sex(M/F) & $14 / 27$ & $17 / 26$ & 0.67 \\
\hline $\begin{array}{l}\text { ASA class I/ } \\
\text { II/III }\end{array}$ & $12 / 11 / 18$ & $16 / 9 / 18$ & 0,69 \\
\hline \multicolumn{4}{|c|}{ The data are presented as the mean \pm SD or the } \\
number, $p>0.05$
\end{tabular}

Analysis of the average duration of surgeries and intra-surgery consumption of anaesthetics shows that there is no significant difference between the two study groups (Table II).

Table II - Duration of surgeries and intraoperative consumption of anaesthetics

\begin{tabular}{|l|c|c|l|}
\hline & $\begin{array}{l}\text { Grup D } \\
(\text { Dexketoprofen }) \\
(\mathrm{n}=41)\end{array}$ & $\begin{array}{l}\text { Grup K } \\
\text { (Ketoprofen) } \\
(\mathrm{n}=43)\end{array}$ & $\mathrm{p}$ \\
\hline $\begin{array}{l}\text { Duration } \\
\text { of surgeries } \\
\text { (min) }\end{array}$ & $78,9 \pm 9,1$ & $84,55 \pm 2,7$ & 0,68 \\
\hline $\begin{array}{l}\text { MAC } \\
\text { (Sevofluran) }\end{array}$ & $0,81 \pm 0,11$ & $0,83 \pm 0,2$ & 0,28 \\
\hline $\begin{array}{l}\text { Fentanyl } \\
\text { (mg) }\end{array}$ & $0,641 \pm 0,14$ & $0,648 \pm 0,13$ & 0,19 \\
\hline $\begin{array}{l}\text { Nalorfina } \\
\text { (mg) }\end{array}$ & $0,23 \pm 0,09$ & $0,27 \pm 0,06$ & 0,57 \\
\hline & & & \\
\hline
\end{tabular}

The data are presented as the mean $\pm S D$ or the number, $p>0.05$ 
Table III - Postoperative analgesia assessed on the visual analogue scale (VAS)

\begin{tabular}{|l|l|c|c|c|c|}
\hline VAS & awaking & at 2 ore & at 6 ore & at 12 ore & at 24 ore \\
\hline $\begin{array}{l}\text { Grupul D (Dexketoprofen) } \\
(\mathrm{n}=41)\end{array}$ & $31,8 \pm 8,6$ & $29,7 \pm 9,8$ & $32,4 \pm 7,9$ & $34,2 \pm 11,6$ & $22,3 \pm 11,5$ \\
\hline $\begin{array}{l}\text { Grupul K (Ketoprofen) } \\
(\mathrm{n}=43)\end{array}$ & $38,2 \pm 11,8$ & $40,8 \pm 5,2$ & $44,2 \pm 8,4$ & $39,1 \pm 8,2$ & $26,4 \pm 11,1$ \\
\hline $\mathrm{p}$ & $0,03^{*}$ & 0,06 & $0,03^{*}$ & 0,07 & 0,06 \\
\hline
\end{tabular}

The data are presented as the mean \pm SD or the number ${ }^{*} \mathrm{p}<0.05$

Analgesia, assessed on the visual analogue scale (VAS), demonstrated to be of high quality for group D patients, when awaking and 6 hours after the surgery $(p<0,05)$ (Table III, Figure 1).

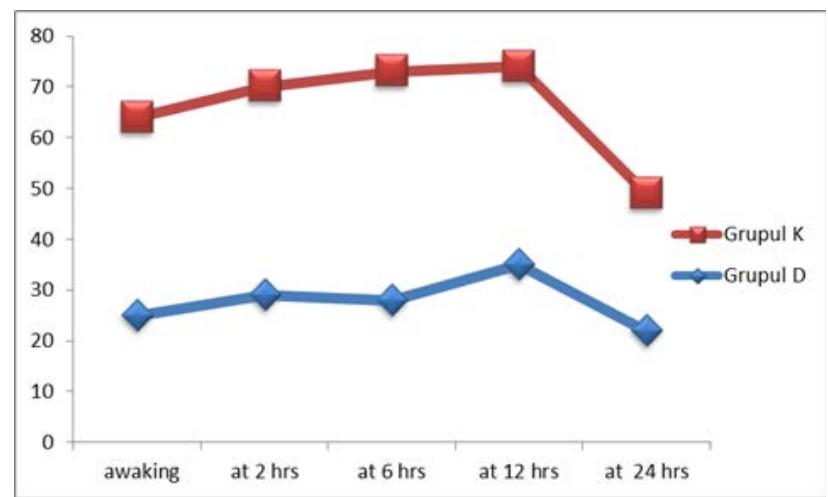

Figure 1 - Visual analog scores (VAS) for the 24 postoperative hours

Both the number of patients who required backup analgesic administration (tramadol), but also its total dose in the first 24 hours were lower in group D compared to group $\mathrm{K}(\mathrm{p}<0,05)$ (Table IV).

Table IV-Consumption of tramadol in the first 24 postoperative hours

\begin{tabular}{|l|c|c|c|}
\hline & $\begin{array}{c}\text { Grup D } \\
(\text { Dexketoprofen }) \\
(\mathrm{n}=41)\end{array}$ & $\begin{array}{c}\text { Grup K } \\
(\text { Ketoprofen }) \\
(\mathrm{n}=43)\end{array}$ & $\mathrm{p}$ \\
\hline Nr. boluses & $1,23 \pm 0,81$ & $3,2 \pm 1,4$ & $0,015^{*}$ \\
\hline $\begin{array}{l}\text { Nr. of } \\
\text { patients } \\
\text { who } \\
\text { required } \\
\text { tramadol }\end{array}$ & 11 & 26 & $0,028^{*}$ \\
\hline
\end{tabular}

The data are presented as the mean $\pm S D$ or the number, ${ }^{*} p<0.05$

There are no cases of intra or post-surgery bleedings. Regarding the incidence of post-surgery nausea and vomiting, this occurred more frequently in patients from group $\mathrm{K}$ than those in group $\mathrm{D}$ (Figure 2).

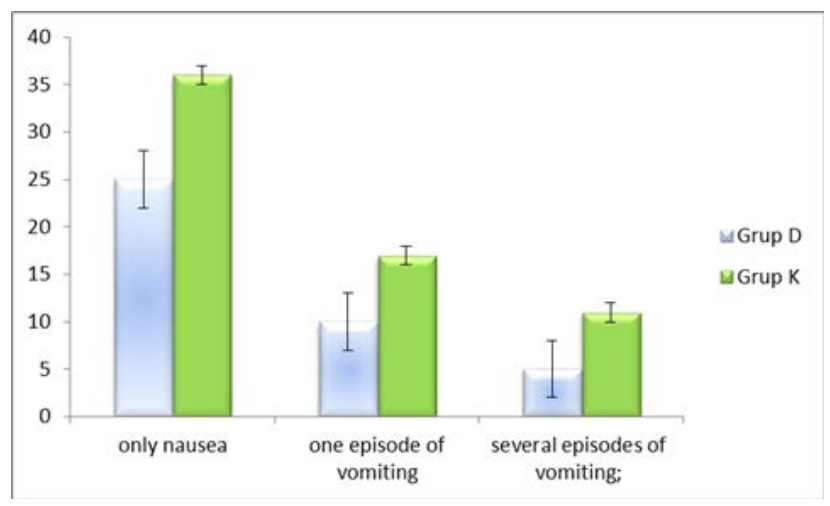

Figure 2 - Incidence of postoperative nausea and vomiting

The hospitalization period of patients included in the study was similar in both groups. (Table V).

Table V - Hospitalization period (days)

\begin{tabular}{|l|c|c|c|}
\hline & $\begin{array}{c}\text { Grup D } \\
(\text { Dexketoprofen }) \\
(\mathrm{n}=41)\end{array}$ & $\begin{array}{c}\text { Grup K } \\
(\text { Ketoprofen }) \\
(\mathrm{n}=43)\end{array}$ & $\mathrm{p}$ \\
\hline $\begin{array}{l}\text { Length of } \\
\text { hospitalization } \\
\text { period }\end{array}$ & $2,68 \pm 1,03$ & $2,75 \pm 0,98$ & 0,72 \\
\hline
\end{tabular}

The data are presented as the mean $\pm S D$ or the number, $p>0.05$ 


\section{Discussions}

The multimodal analgesia is routinely given after laparoscopic cholecystectomy. The PROSPECT group has drawn up recommendations in this regard based on 121 randomized and controlled clinical studies published between 1996 and 2006 [7]. An excellent systematic review of the literature regarding the use of different analgesic techniques after laparoscopic cholecystectomy was published in 2006 by Thue Bisgaard [4].

Inflammatory drugs (NSAIDs) are part of the basic therapeutic means to combat acute postoperative pain. In this class of drugs, heterogeneity of molecular structure causes a different inhibition of cyclooxygenase (COX) both in terms of the COX1 - COX2 selectivity, and in terms of penetration of the central nervous system [8]. Ketoprofen has a biochemical profile which allows the rapid crossing of the blood-brain barrier and can include effective analgesia through both peripheral and central mechanisms [8,9]. Furthermore, the stereoisomer, Dexketoprofen is characterized by higher analgesic potency and fast onset of action due to high fat solubility. Mazario et al's study demonstrates the inhibition of prostaglandin synthesis and nociceptive spinal reflexes $[3,4]$. The association of inflammatory drugs and paracetamol has shown to decrease the opioid requirements by approximately $20-30 \%$ for each of the two classes of substances[2,7] .

In our study we find superiority conferred to analgesia due to the use of dexketoprofen, patients in group D having pain scores on awakening and 6 hours after the surgery, statistically significant lower than patients in group $\mathrm{K}$.

The incidence and severity of postoperative nausea and vomiting was lower in group D compared to group $\mathrm{K}$, probably due to the decrease of the necessary effective tramadol and analgesia obtained by the pre-emptive administration of dexketoprofen.

It is interesting to note that no patient had adverse reactions associated with intravenous administration of NSAIDs, also probably due to a combination of the routine anti $\mathrm{H} 2$ (ranitidine).
As limitations of the study, the relatively small number of patients and lack of qualitative differentiation of pain (somatic, visceral, pain irradiated to the shoulder - relatively specific for laparoscopic cholecystectomy) should be mentioned.

\section{Conclusions}

Dexketoprofen ensures superior analgesia to ketoprofen in the immediate post-surgery period after the laparoscopic cholecystectomy. Pre-emptive use of NSAIDs reduces the dose and frequency of backup analgesic use (tramadol) and decreases the incidence and severity of post-surgery nausea and vomiting. For a better differentiation of the two analgesics evaluated, thorough studies are required which should involve a large number of patients.

\section{References}

1. Abdulla, S., Eckhardt, R., Netter, U. \& Abdulla, W. (2012). A randomized doubleblind, controlled trial on non-opioid analgesics and opioid consumption for postoperative pain relief after laparoscopic cholecystectomy. Acta Anaesth. Belg. 63, 43-50

2. Wills, V.L. \& Hunt, D.R. (2000). Pain after laparoscopic cholecystectomy. Br J Surg. 87, 273-84

3. Lepner, U., Goroshina, J. \& Samarutel, J. (2003). Postoperative pain relief after laparoscopic cholecystectomy: A randomised prospective double-blind clinical trial. Scand J Surg. 92, 121-4

4. Bisgaard, T. (2006). Analgesic treatment after laparoscopic cholecystectomy: a critical 
assessment of the evidence. Anesthesiology. 104(4), 835-846

5. Akaraviputh, T., Leelouhapong, C., Lohsiriwat, V. \& Aroonpruksakul, S. (2009) Efficacy of perioperative parecoxib injection on postoperative pain relief after laparoscopic cholecystectomy: A prospective, randomized study. World J Gastroenterol. 15(16), 2005-2008

6. Bisgaard, T., Kehlet, H. \& Rosenberg, J. (2001). Pain and convalescence after laparoscopic cholecystectomy. Eur J Surg. 167, 84-96

7. Salihoglu, Z., Yildirim, M., Demiroluk, S., Kaya, G., Karatas, A. \& Ertem, M. et al. (2009). Evaluation of intravenous paracetamol administration on postoperative pain and recovery characteristics in patients undergoing laparoscopic cholecystectomy. Surg Laparosc Endosc Percutan Tech. 19, 321-323
8. Buland, K., Zahoor, M.U., Asghar, A., Khan, S. \& Zaid, A.Y. (2012). Efficacy of single dose perioperative intravenous steroid (dexamethasone) for postoperative pain relief in tonsillectomy patients. J Coll Physicians Surg Pak. 22, 349-352

9. Maestroni, U., Sortini, D., Devito, C., Pour Morad Kohan Brunaldi F., Anania, G., Pavanelli, L., Pasqualucci, A. \& Donini, A. (2002). A new method of preemptive analgesia in laparoscopic cholecystectomy. Surg Endosc. 16, 1336-40 